\title{
Ultrastructure and biochemical studies of the flagellar sheath of Helicobacter pylori
}

\author{
G. GEIS, S. SUERBAUM*, B. FORSTHOFF, H. LEYING $\dagger$ and W. OPFERKUCH
}

Department of Medical Microbiology and Immunology, Ruhr-Universität Bochum, D-4630 Bochum, Germany

\begin{abstract}
Summary. Helicobacter pylori flagellar sheaths were isolated by sucrose density-gradient centrifugation and analysed by electronmicroscopy, SDS-PAGE and gas-liquid chromatography. Electronmicroscopy of thin sections of flagella showed an internal electron-dense filament and a surrounding flagellar sheath with the typical bilayer structure of a membrane. The flagellar filaments could be disintegrated by acid treatment and the resulting isolated flagellar sheaths formed vesicles, sometimes with characteristic structures. Centrifugation of flagellar preparations after acid treatment resulted in the enrichment of flagellar sheaths in the pellet. SDS-PAGE analysis of the pellet showed a reduction of the flagellin band and a number of protein bands of 150, 76, 67, 65, 53, 51, 49, 29.5, 18, 17 and $16 \mathrm{kDa}$. However, there were no major protein bands characteristic for the sheath. Differences between the protein profiles of Sarkosyl-insoluble membranes and flagellar sheaths appeared in the lower $M_{r}$ range of 30-14 kDa. Major fatty acids of isolated flagellar sheaths were C 14:0, C 19:0 cyc, $\mathrm{C} 18: 0$, and the LPS-specific fatty acids 3-OH C 16:0 and 3-OH C 18:0. The results demonstrate that the flagellar sheaths of $H$. pylori are membranes and contain LPS and proteins.
\end{abstract}

\section{Introduction}

Helicobacter pylori is the aetiological agent of chronic type b gastritis in man. H. pylori gastritis is a major predisposing factor for peptic, duodenal and gastric ulcers ${ }^{1-5}$ and is possibly involved in the pathogenesis of gastric cancer. ${ }^{6,7}$ Several components of this bacterium have been suggested to be virulence factors but only urease expression ${ }^{8}$ and motility ${ }^{9}$ have been shown to be associated with bacterial virulence in animal models.

Motility is conferred on the bacteria by two to six polar flagella with a very characteristic and unusual morphology. Each flagellum consists of a central filament enveloped by a flagellar sheath. The filament consists mainly of polymers of a $53-\mathrm{kDa}$ flagellin and the gene encoding this protein has recently been cloned and sequenced. ${ }^{10}$ Whereas the filaments of $H$. pylor have been characterised in detail ${ }^{11-13}$ there are almost no data on the structure and function of the flagellar sheath. Flagellar sheaths have been described in only a few bacterial species such as Vibrio cholerae,${ }^{14}$ Pseudomonas stizolobii ${ }^{15}$ and Bdellovibrio bacteriovorus. ${ }^{16}$ However, they seem to be common to all species of the genus Helicobacter. ${ }^{17}$

Received 20 Aug. 1992; revised version accepted 18 Nov. 1992

* Present address: Unité des Entérobactéries, Institut Pasteur, 28 rue du Dr. Roux, F-75724 Paris, France.

† Present address: Boehringer Mannheim GmbH, Nonnenwald 2, D-8122 Penzberg, Germany.
The only flagellar sheaths that have been characterised in detail are those of $V$. cholerae and B. bacteriovorus. Fuerst and Perry ${ }^{18}$ have clearly demonstrated by protein A-gold immuno-electronmicroscopy that the flagellar sheath of $V$. cholerae contains lipopolysaccharides (LPS). Hranitzky et al ${ }^{19}$ reported that the sheath contains a protein, composed of three polypeptides, which is also present in the outer membrane of $V$. cholerae. Thomashow and Rittenberg ${ }^{20}$ found that the flagellar sheath of $B$. bacteriovorus had a characteristic composition of lipids and LPS when compared with whole bacteria.

Although there are as yet no data to support the hypothesis, it is likely that the sheath of $H$. pylori plays a role in the pathogenic process. Possible functions are protection of the filament from disintegration in the acidic environment of the stomach ${ }^{21}$ and promotion of adherence. We have performed ultrastructural and biochemical studies of the $H$. pylori flagellar sheath to obtain information about the composition of this structure, which will eventually contribute to a better understanding of its function.

\section{Materials and methods}

\section{Bacteria}

H. pylori strain 898-1 was used. To obtain sufficient bacteria for sheath preparation, 2-L Erlenmeyer flasks 
were filled with $1.6 \mathrm{~L}$ of supplemented brain heart infusion broth ${ }^{11}$ and inoculated with $120 \mathrm{ml}$ of a liquid culture of $H$. pylori. Flasks were incubated for 3 days in air with $\mathrm{CO}_{2} 9 \% \mathrm{v} / \mathrm{v}$ at $37^{\circ} \mathrm{C}$ and agitated with a magnetic stirrer $(100 \mathrm{rpm})$. By this method, a yield of $1 \mathrm{~g}$ (wet weight) of bacterial of culture was achieved. Bacteria were harvested by centrifugation $(7000 \mathrm{~g}$ for $20 \mathrm{~min}$ at $10^{\circ} \mathrm{C}$ ), washed once in $\mathrm{NaCl} 0.9 \% \mathrm{w} / \mathrm{v}$, centrifuged again, and resuspended in $0.01 \mathrm{M}$ Tris$\mathrm{HCl}, \mathrm{pH} 7.2$, to a concentration of $c .0 .05 \mathrm{~g}$ of bacteria $/ \mathrm{ml}$ of buffer.

\section{Preparation of flagellar sheaths}

Bacteria (6.3 g wet weight) were sheared in a Sorvall Omni-Mixer for $5 \mathrm{~min}$ on ice. Bacterial cells were removed by centrifugation $\left(3500 \mathrm{~g}\right.$ for $10 \mathrm{~min}$ at $10^{\circ} \mathrm{C}$ ) and the flagella were harvested from the supernate by ultracentrifugation $\left(270000 \mathrm{~g}\right.$ for $1 \mathrm{~h}$ at $\left.10^{\circ} \mathrm{C}\right)$. Flagella were suspended in $0.01 \mathrm{M}$ Tris- $\mathrm{HCl}, \mathrm{pH} \mathrm{7.2,} \mathrm{and}$ transferred to a linear sucrose density gradient (sucrose $25.65 \% \mathrm{w} / \mathrm{w}$ in $0.01 \mathrm{M}$ Tris- $\mathrm{HCl}, \mathrm{pH} \mathrm{7.2).} \mathrm{The}$ gradients were centrifuged for $22 \mathrm{~h}$ at $100000 \mathrm{~g}$ at $10^{\circ} \mathrm{C}$. A fluffy layer that had formed at the top of the gradients was removed with a pasteur pipette and the gradient was subsequently separated into fractions of 0.7-1.2 ml with an Auto-Densi Flow device (HaakeBuchler, Saddle Brook, USA). The $\mathrm{OD}_{280}$ was monitored continuously with a Uvicord (LKB, Bromma, Sweden). Fractions 14-19 and 22-26 (fig. 1, peaks I and II, respectively) were each pooled, diluted with water, pelleted by ultracentrifugation $(270000 \mathrm{~g}$ for $2 \mathrm{~h}$ at $10^{\circ} \mathrm{C}$ ), and resuspended in water.

\section{Disintegration of filaments}

For disintegration by acid treatment, peak I material was mixed slowly with drops of $0.01 \mathrm{~N} \mathrm{HCl}$ until the $\mathrm{pH}$ reached $2 \cdot 0$. The solution was centrifuged in Eppendorf tubes $\left(15800 \mathrm{~g}\right.$ for $30 \mathrm{~min}$ at $\left.4^{\circ} \mathrm{C}\right)$, the pellet was resuspended in distilled water, and both pellet and supernate were neutralised with $1 \mathrm{~N} \mathrm{NaOH}$. Other samples of peak I material were treated with proteinase $\mathrm{K}(5 \mathrm{mg} / \mathrm{ml})$ for $60 \mathrm{~min}$ and $120 \mathrm{~min}$ at $37^{\circ} \mathrm{C}$ or at room temperature. Trypsin $(200 \mathrm{IU} / \mathrm{ml})$ was mixed with peak I material and incubated for 30,60 and $180 \mathrm{~min}$ at $37^{\circ} \mathrm{C}$.

\section{Preparation of outer membranes by detergent solubilisation}

Sarkosyl-insoluble membranes were prepared by a modification of the method of Achtman et al.$^{22}$ Briefly, bacteria were harvested from broth cultures and washed twice with phosphate-buffered saline or $\mathrm{NaCl}$ $0.9 \% \mathrm{w} / \mathrm{v}$. The bacterial pellet was resuspended in $10 \mathrm{~mm}$ Tris- $\mathrm{HCl}, \mathrm{pH} 7 \cdot 2$, sheared in an Omni-Mixer and then sonicated for four periods of $30 \mathrm{~s}$ in ice (Branson sonifier). Unbroken cells were removed by centrifugation $(3000 \mathrm{~g}$ for $10 \mathrm{~min})$ and membranes were pelleted by ultracentrifugation $(48000 \mathrm{~g}$ for $1 \mathrm{~h}$ at $10^{\circ} \mathrm{C}$ ). The pellet was resuspended in $12.5 \mathrm{~mm}$ Tris$\mathrm{HCl}$, pH 7.6 containing Sarkosyl $1.88 \% \mathrm{w} / \mathrm{v}$ and incubated for $1 \mathrm{~h}$ at room temperature with agitation. Sarkosyl-insoluble outer membranes were collected by ultracentrifugation $\left(48000 \mathrm{~g}\right.$ for $90 \mathrm{~min}$ at $20^{\circ} \mathrm{C}$ ) and resuspended in distilled water.

\section{Analytical methods}

Protein content was assessed by the method of Markwell et al. ${ }^{23}$ or Smith et al. ${ }^{24}$ and SDS-PAGE was as described by Lugtenberg $e t$ al ${ }^{25}$ The concentration of acrylamide in the separating gel was $11 \% \mathrm{w} / \mathrm{v}$ and a $60-\mu \mathrm{g}$ sample of protein was applied to each slot of the gel. Protein mixtures of myosin $(205 \mathrm{kDa}), \beta$ galactosidase $(116 \mathrm{kDa})$, phosphorylase b $(94 \mathrm{kDa})$, albumin $(67 \mathrm{kDa})$, ovalbumin $(43 \mathrm{kDa})$, carbonic anhydrase $(30 \mathrm{kDa})$, trypsin inhibitor $(20 \cdot 1 \mathrm{kDa})$ and $\alpha$-lactalbumin $(14.4 \mathrm{kDa})$ were used as standards for mol. wt determination.

Fatty acid methyl esters were prepared according to method A of Gmeiner and Martin ${ }^{26}$ and analysed by gas liquid chromatography as described previously. ${ }^{27}$

\section{Electronmicroscopy}

Negative staining was performed by applying samples to formvar-carbon coated grids and contrasting with phosphotungstic acid, $\mathrm{pH} 7$.

For thin sectioning, flagella (peak I material) were pelleted by ultracentrifugation. After overnight fixation in Karnowsky buffer, flagellar sheaths were postfixed in osmium tetroxide $1 \% \mathrm{w} / \mathrm{v}$, dehydrated in a graded series of ethanol, and embedded in Epon. Thin sections were stained with uranyl acetate and lead citrate.

\section{Results}

\section{Preparation of $H$. pylori flagellar sheaths}

Flagella were detached mechanically from the cells by shearing, and the flagella-containing material was subjected to sucrose density-gradient centrifugation (fig. 1). Two major peaks were observed and analysed by electronmicroscopy. Peak I (buoyant density $1 \cdot 187 \mathrm{~g} / \mathrm{cm}^{3}$ ) contained flagella and sheaths (fig. 2) and showed a marked (c. 5-10-fold) enrichment of sheaths as compared with peak II (buoyant density $1.213 \mathrm{~g} / \mathrm{cm}^{3}$ ), which contained predominantly naked filaments (not shown). The peak I components could not be separated further by subsequent gradient centrifugations.

\section{Ultrastructure}

Ultrathin sections of peak I material confirmed the large amount of flagellar sheaths in this preparation (fig. 3). The sheath exhibited the typical picture of a 


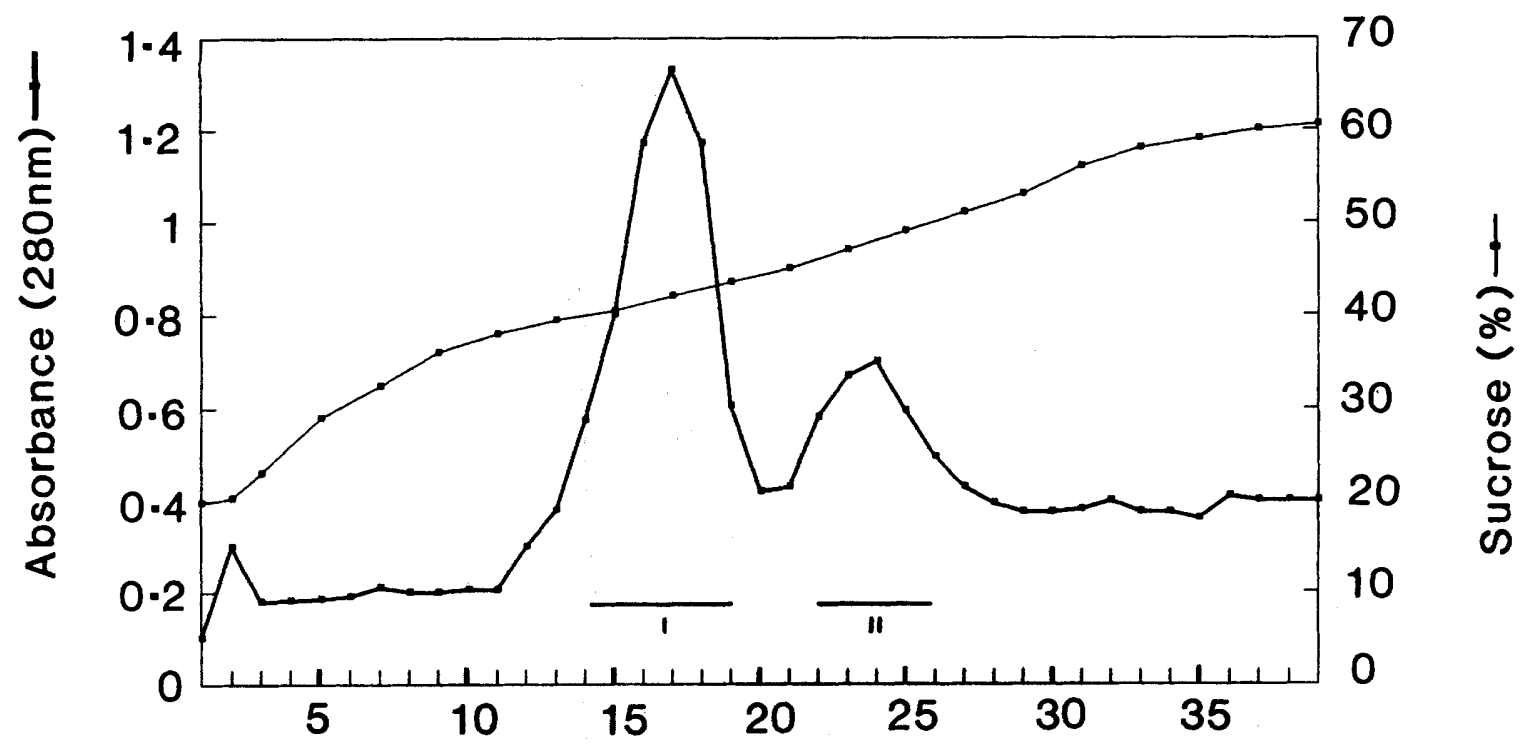

Fraction no.

Fig. 1. Distribution of flagellar preparation after sucrose density-gradient centrifugation. Fractions were pooled (peaks I and II) as indicated below the curve.

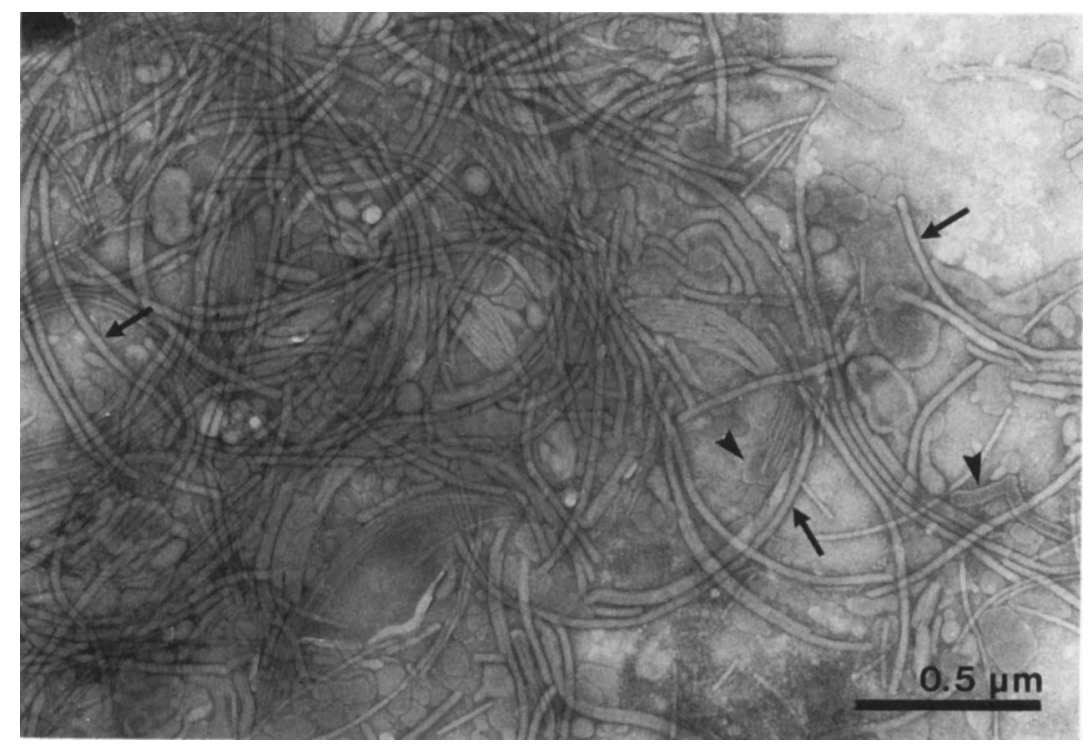

Fig. 2. Electronmicrograph of the material contained in peak I. Sheathed flagella can be distinguished from filaments by their greater diameter. Note the high amount of sheathed flagella $(\rightarrow)$ and empty sheaths $($ ).

bilayered membrane with two parallel electron-dense lines. Inside the membrane rings, the flagellar filament appeared as an electron-dense structure $12-14 \mathrm{~nm}$ in diameter. Contaminating membrane vesicles could be distinguished easily from flagellar sheaths because of their greater size and the absence of internal filaments. The diameter of sheath cross-sections varied considerably, consistent with the different degrees of detachment of 'the sheath from the filament seen in negatively-stained preparations of isolated flagella.

Since the filaments could not be removed by physical methods, attempts were made to separate the sheaths and filaments by differential solubilisation methods. Treatments with SDS $0.1-0.4 \% \mathrm{w} / \mathrm{v}$ resulted in the parallel dissolution of both filaments and sheaths. Proteinase $\mathrm{K}$ and trypsin treatments did not lead to structural changes of the material. In contrast, incubation in the presence of $0.01 \mathrm{M} \mathrm{HCl}(\mathrm{pH} \mathrm{2.0)}$ resulted in the dissolution of the filaments while the sheaths retained their membranous appearance. Fig. 4 shows the effects of $\mathrm{HCl}$ treatment on the partiallypurified flagellar sheaths (peak I material). Isolated flagellar sheaths formed vesicles after filament disintegration. Most vesicles had a rather characteristic "cherry-shaped" appearance with a stem-like part, in which the sheath had collapsed, and a second, vesicular part.

\section{SDS-PAGE analysis of flagellar sheaths}

Isolated flagella containing flagellar sheaths and flagellar filaments were subjected to $\mathrm{HCl}$ treatment 


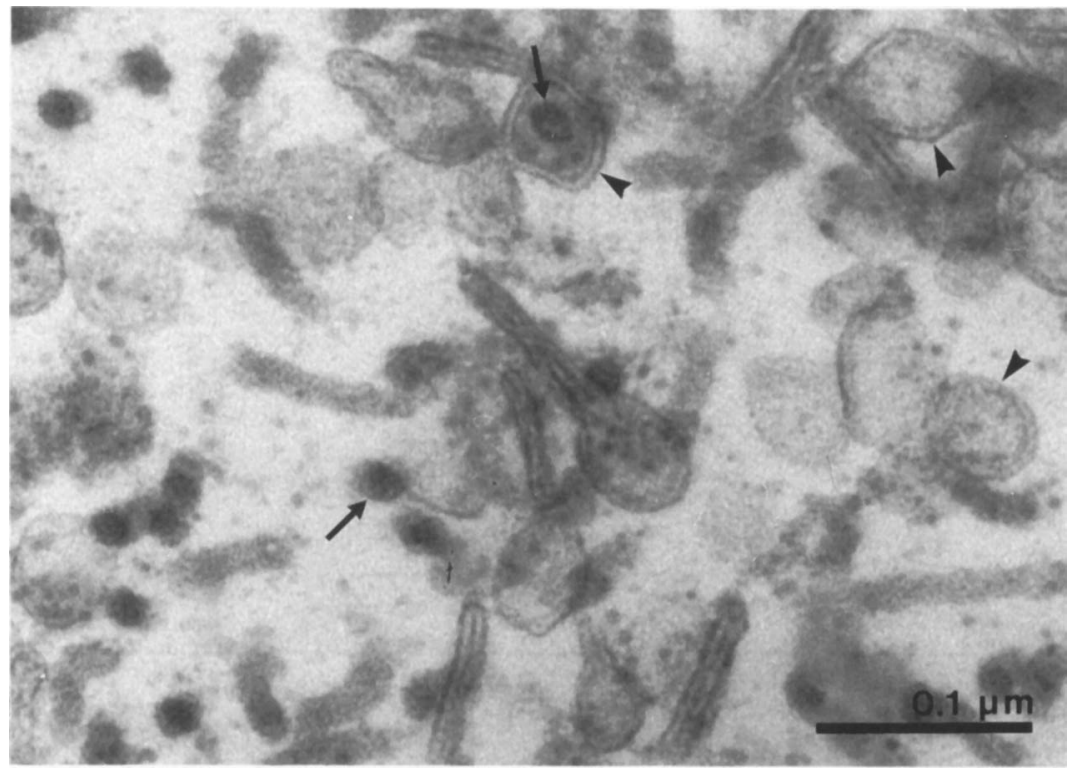

Fig. 3. Thin section of a preparation of sheathed flagella (peak I material). Note the bilayer structure of flagellar sheath ( ) and the internal electron-dense filament $(\rightarrow)$

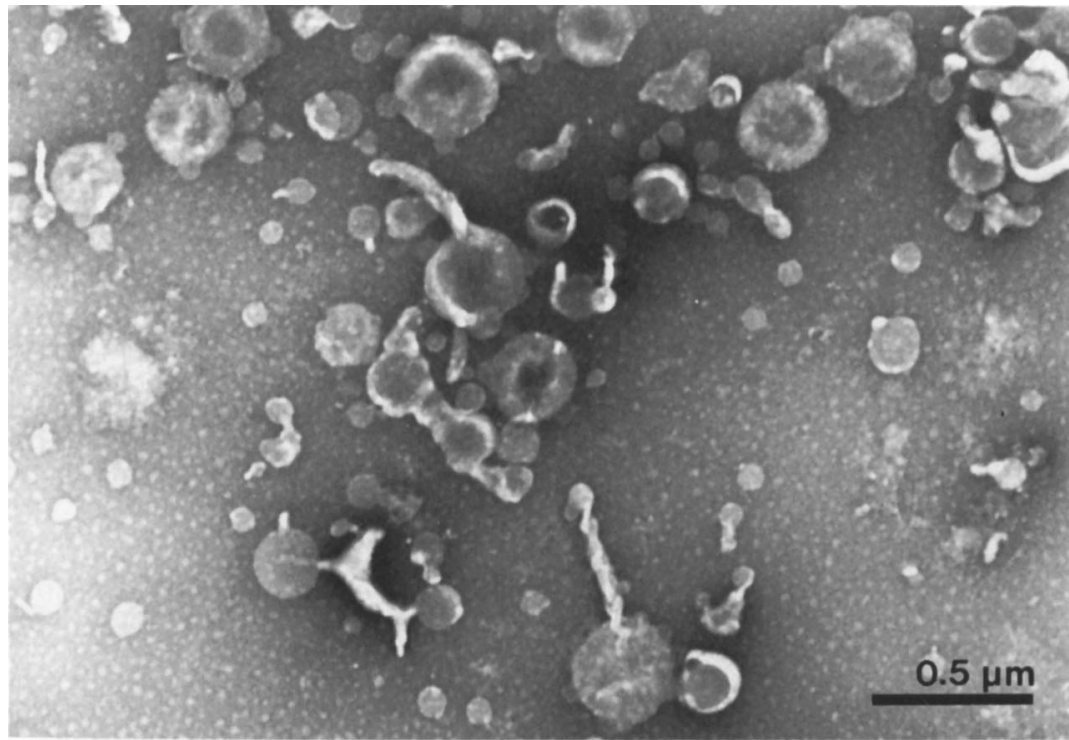

Fig. 4. Electronmicrograph of partially purified flagellar sheaths (peak I material after $\mathrm{HCl}$ treatment). There are no filaments. The sheaths form vesicles some of which carry stem structures.

and centrifugation. Protein profiles (fig. 5) obtained by SDS-PAGE showed that the flagellar filaments had been almost completely solubilised by acid treatment leading to a heavily enriched flagellin band ( $53 \mathrm{kDa})$ in the supernate (lane 3 ). The corresponding pellet (lane 4) showed a multitude of protein bands and only slightly prominent major bands with molecular masses of 76,67 and $65 \mathrm{kDa}$ (possibly the large urease subunit ${ }^{28}$ ), $53 \mathrm{kDa}$ (flagellin band), 51,49 and $29.5 \mathrm{kDa}$ (possibly the small urease subunit ${ }^{28}$ ), 18, 17 and $16 \mathrm{kDa}$, and a characteristic band of $150 \mathrm{kDa}$. The most remarkable differences between the protein profiles of the supernate (lane 3) and the pellet (lane 4) were the reduction of the flagellin band and the enrichment of the $150,72,67,51,49$ and $29.5 \mathrm{kDa}$ bands (arrowheads) in the pelleted material. However, the $150-\mathrm{kDa}$ band could not be seen with equal intensity in protein profiles of different sheath prepara- tions. For comparison with outer-membrane profiles, lane 5 shows the protein profile of Sarkosyl-insoluble membranes (outer membranes). Major Sarkosylinsoluble membrane protein bands were of $M_{r} 150,72$, $67,65,53,51,49,22,21$ and $18 \mathrm{kDa}$. Nearly all protein bands in the $M_{r}$ range $200-30 \mathrm{kDa}$ present in the Sarkosyl-insoluble material were also present in the sedimentable material after $\mathrm{HCl}$ treatment, but in different amounts. Major differences appeared in the lower $M_{r}$ range of $30-14 \mathrm{kDa}$ where the 22- and 21$\mathrm{kDa}$ protein bands were remarkably enriched in the Sarkosyl-insoluble membranes.

\section{Fatty acid composition of flagellar sheaths}

The fatty acid composition of $H$. pylori flagellar sheaths was analysed to determine whether LPSspecific fatty acids were present in the sheaths and if 


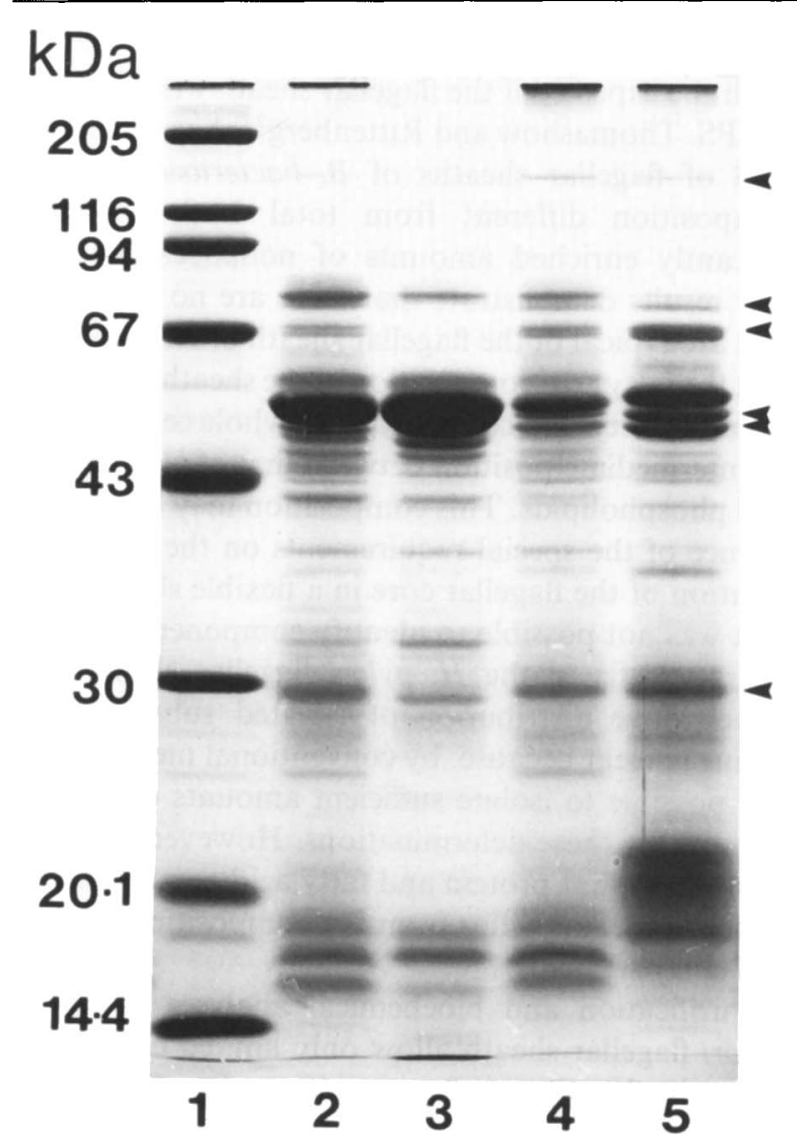

Fig. 5. Protein profiles of $H$. pylori flagella, flagellar sheaths after $\mathrm{HCl}$ treatment, and Sarkosyl-insoluble membranes, obtained by SDS-PAGE. Lane 1: standard proteins; 2: flagella isolated by shearing and centrifugation steps; 3 : supernate; 4: pellet after centrifugation of $\mathrm{HCl}$-treated flagella; 5 : Sarkosyl-insoluble membranes.

there were fatty acids characteristic for the sheath. The most prominent fatty acid of the sheath material was myristic acid (C 14:0). Other major fatty acids were 19-carbon-cyclopropane fatty acid (C 19:0 cyc), $\beta$ hydroxypalmitic acid (3-OH C 16:0), $\beta$-hydroxystearic acid (3-OH C 18:0) and stearic acid (C 18:0). Minor amounts of palmitic acid (C 16:0), oleic acid (C 18:1) and linoleic acid (C 18:2) were also detected (table). Previously published data $^{27}$ about LPS and phospholipid fatty acids are also given in the table to facilitate data interpretation. The relatively high amounts of the LPS-specific fatty acids (3-OH C 16:0,
3-OH C 18:0, C 18:0) strongly suggest that LPS is a part of the sheaths. There was no sheath-specific fatty acid, although the profiles differed significantly from those obtained for cellular fatty acids or phospholipid or LPS fatty acids.

\section{Discussion}

The flagellar filaments of $\mathrm{H}$. pylori, ${ }^{29} \mathrm{H}$. mustelae, ${ }^{30}$ $H$. cinaedi, ${ }^{17,31} H$. fennelliae $e^{17,31}$ and $H$. felis ${ }^{32}$ are enveloped by sheaths and are surface structures possibly involved in the pathogenicity of these bacteria. Until now there has been no information concerning the structure and function of $H$. pylori flagellar sheaths, probably because of difficulties in the isolation of sufficient amounts for qualitative and, especially, quantitative studies. There is also very little information concerning flagellar sheaths of other bacteria and only those of $V$. cholerae $e^{18,19}$ and $B$. bacteriovorus ${ }^{20}$ have been characterised in some detail.

Since it seems likely that these surface structures play a role in pathogenesis, we have performed ultrastructural and biochemical studies of the flagellar sheath of $H$. pylori to find out if it contains characteristic components. An important pre-requisite was the isolation of intact flagellar sheaths. After sucrose density-gradient centrifugation of flagella, one peak (I) was enriched in flagellar sheaths and contained only minor amounts of filaments.

Further separation of flagellar sheaths and filaments was not possible by physical methods, so $\mathrm{HCl}$ treatment was used to release and disintegrate flagellar filaments. Acid treatment has been used successfully with Salmonella, ${ }^{33}$ Wolinella $^{34}$ and Campylobacter spp. $^{35}$ to disintegrate flagellar filaments. With $H$. pylori, disintegration of isolated flagella with $\mathrm{HCl}$ showed that flagellar-sheath vesicles were still visible and the sheaths sometimes even kept their linear structure, possibly because of interactions between the protein constituents. However, isolated flagella could not be separated completely into flagellar sheaths and flagellin molecules. Centrifugation of the acid-treated flagella and SDS-PAGE analysis of the resulting pellet, corresponding mainly to flagellar sheaths, showed a

Table. Fatty acid composition of $H$. pylori flagellar sheaths in comparison to cellular fatty acids and fatty acids of isolated phospholipids and LPS

\begin{tabular}{lccccccccc}
\hline \multirow{1}{*}{ Preparation } & \multicolumn{8}{c}{ Percentage of total fatty acids* that were } \\
\cline { 2 - 9 } & C 14:0 & C 16:0 & C 18:0 & C 18:1 & C 18:2 & C 19:0 cyc & 3-OH C 16:0 & $3-0 H$ C 18:0 \\
\hline Whole cells & 45 & 4 & 8 & 6 & tr & 23 & 5 & 2 \\
Flagellar sheaths & 38 & 5 & 8 & 3 & 2 & 11 & 9 & 8 \\
LPS $\dagger$ & 4 & 2 & 21 & $<0.5$ & $<0.5$ & $<0.5$ & 25 & 24 \\
Phospholipids $\dagger$ & 41 & 7 & 5 & 7 & 2 & 28 & $<0.5$ & $<0.5$ \\
\hline
\end{tabular}

tr, Traces, i.e., 0.5-1.9\%.

* The number before the colon refers to the number of carbon atoms, and the number after the colon refers to the numbers of double bonds; cyc, cyclopropane fatty acid; $\mathrm{OH}$, hydroxyl group.

+ Data taken from Geis et al ${ }^{27}$ 
great reduction of the flagellin band, but it was still visible. This is in contrast to the fact that the filaments could not be seen by electronmicroscopy. A possible explanation could be a "trapping" of the flagellin molecules in the sheath vesicles. This is supported by the finding that a further reduction of the flagellin contamination could be achieved by sonication (data not shown).

Comparisons of sheath preparations with outer membranes of sheared bacteria showed that there were no protein bands typical of the flagellar sheath, but that some protein bands of 150,51 and $49 \mathrm{kDa}$ were enriched. However, we could not always detect the 150-kDa protein band in different sheath preparations (data not shown). The absence of typical flagellar sheath proteins may be compared with the finding of Hranitzky et al. ${ }^{19}$ who reported that flagellar sheaths of $V$. cholerae contain "sheath-proteins" of $61 \cdot 5,60$ and $56.5 \mathrm{kDa}$, which are also present in the $V$. cholerae outer membrane.

Biochemical analyses of fatty acids were performed to clarify the existence of LPS as a constituent of $H$. pylori flagellar sheaths, because this point has been discussed controversially in relation to $V$. cholerae. ${ }^{18.19}$ H. pylori LPS contains very characteristic fatty acids ${ }^{27}$ and these can serve as markers for the existence of LPS in the sheaths. Analyses revealed that fatty acids $3-\mathrm{OH}$ $\mathrm{C} 16: 0$ and 3-OH C 18:0 were present in flagellar sheaths, leading to the conclusion that the sheaths of $H$. pylori do indeed contain LPS. For $V$. cholerae, it was originally postulated that the flagellar sheaths do not carry LPS, ${ }^{19}$ but Fuerst et al. ${ }^{18}$ have clearly demonstrated the presence of LPS in $V$. cholerae flagellar sheaths by immuno-gold electronmicroscopy. In $H$. pylori, comparison of the fatty acid composition of flagellar sheaths and whole cells showed higher amounts of the LPS-specific fatty acids 3-OH C 16:0

\section{References}

1. Peterson WL. Helicobacter pylori and peptic ulcer disease. $N$ Engl J Med 1991; 324: 1043-1048.

2. Blaser MJ. Epidemiology and pathophysiology of Campylobacter pylori infections. Rev Infect Dis 1990; 12 Suppl 1: S99-S106.

3. Goodwin CS, Armstrong JA. Microbiological aspects of Helicobacter pylori (Campylobacter pylori). Eur J Clin Microbiol Infect Dis 1990; 9: 1-13.

4. Dick JD. Helicobacter (Campylobacter) pylori: a new twist to an old disease. Annu Rev Microbiol 1990; 44: 249-269.

5. Buck GE. Campylobacter pylori and gastroduodenal disease. Clin Microbiol Rev 1990; 3: 1-12.

6. Parsonnet J, Friedman GD, Vandersteen DP et al. Helicobacter pylori infection and the risk of gastric carcinoma. $N$ Engl $J$ Med 1991 ; 325: 1127-1131.

7. Nomura A, Stemmermann GN, Chyou P-H, Kato I, PerezPerez GI, Blaser MJ. Helicobacter pylori infection and gastric carcinoma among Japanese Americans in Hawaii. $N$ Engl J Med 1991; 325: 1132-1136.

8. Eaton KA, Brooks CL, Morgan DR, Krakowka S. Essential role of urease in pathogenesis of gastritis induced by Helicobacter pylori in gnotobiotic piglets. Infect Immun 1991; 59: 2470-2475.

9. Eaton KA, Morgan DR, Krakowka S. Campylobacter pylori and 3-OH C 18:0 in the sheaths, but less $C$ 18:0 than might be expected if the flagellar sheath were enriched in LPS. Thomashow and Rittenberg ${ }^{20}$ showed that the LPS of flagellar sheaths of $B$. bacteriovorus has a composition different from total LPS, with significantly enriched amounts of nonadecanoic acid. Our results demonstrate that there are no fatty acids that are typical of the flagellar sheath of $H$. pylori, but that the fatty acid composition of the sheath is different from the fatty acid composition of whole cells, and has an intermediate position between that of isolated LPS and phospholipids. This composition may be a consequence of the special requirements on the sheath for rotation of the flagellar core in a flexible sheath. ${ }^{36}$

It was not possible to identify components that are characteristic of the $H$. pylori flagellar sheath. The quantitative distribution of isolated substances remains unclear because, by conventional methods, it is not possible to isolate sufficient amounts of flagellar sheaths for these determinations. However, there are some hints that protein and fatty acid composition of flagellar sheaths differ from the composition of other cell compartments.

Purification and biochemical analyses of the $H$. pylori flagellar sheath allow only limited conclusions about its function and composition. For $V$. cholerae, Richardson et al ${ }^{37,38}$ constructed $f a A$-negative mutants which had empty sheaths. The $H$. pylori flaA gene has been cloned and sequenced ${ }^{10}$ and experiments are under way concerning the mutagenesis of this gene. Construction of mutants that do not carry flagellar filaments would lead to the identification of flagellar sheath components and clarify the role of the sheath in pathogenesis, e.g., in adherence and inhibition of acid secretion.

We thank Professor K. Meller for thin sections of flagellar sheaths and Dr Sabine Birkholz for critically reading the manuscript. virulence factors in gnotobiotic piglets. Infect Immun 1989; 57: 1119-1125.

10. Leying H, Suerbaum S, Geis G, Haas R. Cloning and genetic characterization of a Helicobacter pylori flagellin gene. Mol Microbiol 1992; 6: 2863-2874.

11. Geis G, Leying H, Suerbaum S, Mai U, Opferkuch W Ultrastructure and chemical analysis of Campylobacter pylori flagella. $J$ Clin Microbiol 1989; 27 : 436-441.

12. Kostrzynska M, Betts JD, Austin JW, Trust TJ. Identification, characterization, and spatial localization of two flagellin species in Helicobacter pylori flagella. J Bacteriol 1991; 173: 937-946.

13. Luke CJ, Kubiak E, Cockayne A, Elliott TS, Penn CW Identification of flagellar and associated polypeptides of Helicobacter (formerly Campylobacter) pylori. FEMS Microbiol Lett 1990; 59: 225-230.

14. Follett EAC, Gordon J. An electron microscope study of Vibrio flagella. J Gen Microbiol 1963; 32: 235-239.

15. Fuerst JA, Hayward AC. The sheathed flagellum of Pseudomonas stizolobii. J Gen Microbiol 1969; 58: 239-245.

16. Seidler RJ, Starr MP. Structure of the flagellum of Bdellovibrio bacteriovorus. J Bacteriol 1968; 95 : 1952-1955.

17. Vandamme $\mathbf{P}$, Falsen $\mathbf{E}$, Rossau $R$ et al. Revision of Campylobacter, Helicobacter, and Wolinella taxonomy: emendation of generic descriptions and proposals of Arcobacter gen. nov. Int J Syst Bacteriol 1991; 41 : 88-103. 
18. Fuerst JA, Perry JW. Demonstration of lipopolysaccharide on sheathed flagella of Vibrio cholerae $\mathrm{O}: 1$ by protein A-gold immunoelectron microscopy. $J$ Bacteriol 1988; 170: 1488-1494.

19. Hranitzky KW, Mulholland A, Larson AD, Eubanks ER, Hart LT. Characterization of a flagellar sheath protein of Vibrio cholerae. Infect Immun 1980; 27: 597-603.

20. Thomashow LS, Rittenberg SC. Isolation and composition of sheathed flagella from Bdellovibrio bacteriovorus 109J. $J$ Bacteriol 1985; 163: 1047-1054.

21. Jones DM, Curry A. The ultrastructure of Campylobacter pylori. In: Rathbone BJ, Heatley RV (eds) Campylobacter pylori and gastroduodenal disease. Oxford, Blackwell Scientific Publications. 1989: 48-59.

22. Achtman M, Mercer A, Kusecek B et al. Six widespread bacterial clones among Escherichia coli $\mathrm{K} 1$ isolates. Infect Immun 1983; 39: 315-335.

23. Markwell MAK, Haas SM, Bieber LL, Tolbert NE. A modification of the Lowry procedure to simplify protein determination in membrane and lipoprotein samples. Anal Biochem 1978; 87: 206-210.

24. Smith PK, Krohn RI, Hermanson GT et al. Measurement of protein using bicinchoninic acid. Anal Biochem 1985; 150: 76-85.

25. Lugtenberg B, Meijers J, Peters R, van der Hoek P, van Alphen L. Electrophoretic resolution of the "major outer membrane protein" of Escherichia coli K12 into four bands. FEBS Lett 1975; 58: 254-258.

26. Gmeiner J, Martin HH. Phospholipid and lipopolysaccharide in Proteus mirabilis and its stable protoplast L-form: difference in content and fatty acid composition. Eur $J$ Biochem 1976; 67: 487-494.

27. Geis G, Leying H, Suerbaum S, Opferkuch W. Unusual fatty acid substitution in lipids and lipopolysaccharides of Helicobacter pylori. J Clin Microbiol 1990; 28: 930-932.

28. Hu LT, Mobley HL. Purification and N-terminal analysis of urease from Helicobacter pylori. Infect Immun 1990; 58 : 992-998.

29. Warren JR, Marshall B. Unidentified curved bacilli on gastric epithelium in active chronic gastritis. Lancet 1983; 1: 1273-1275.

30. Goodwin CS, Armstrong JA, Chilvers T et al. Transfer of Campylobacter pylori and Campylobacter mustelae to Helicobacter gen. nov. as Helicobacter pylori comb. nov. and Helicobacter mustelae comb. nov., respectively. Int $J$ Syst Bacteriol 1989; 39: 397-405.

31. Han Y-H, Smibert RM, Krieg NR. Occurrence of sheathed flagella in Campylobacter cinaedi and Campylobacter fennelliae. Int J Syst Bacteriol 1989; 39: 488-490.

32. Paster BJ, Lee A, Fox JG et al. Phylogeny of Helicobacter felis sp. nov., Helicobacter mustelae, and related bacteria. Int $J$ Syst Bacteriol 1991; 41: 31-38.

33. Aizawa SI, Dean GE, Jones CJ, Macnab RM, Yamaguchi S. Purification and characterization of the flagellar hookbasal body complex of Salmonella typhimurium. $J$ Bacteriol 1985; 161: 836-849.

34. Kupper J, Wildhaber I, Gao Z, Baeuerlein E. Basal-bodyassociated disks are additional structural elements of the flagellar apparatus isolated from Wolinella succinogenes. $J$ Bacteriol 1989; 171: 2803-2810.

35. Logan SM, Trust TJ. Molecular identification of surface protein antigens of Campylobacter jejuni. Infect Immun 1983; 42: 675-682.

36. Fuerst JA. Bacterial sheathed flagella and the rotary motor model for the mechanism of bacterial motility. J Theor Biol $1980 ; 84: 761-774$.

37. Richardson K, Nixon L, Mostow P, Kaper JB, Michalski J. Transposon-induced non-motile mutants of Vibrio cholerae. J Gen Microbiol 1990; 136: 717-725.

38. Richardson $\mathbf{K}$. Roles of motility and flagellar structure in pathogenicity of Vibrio cholerae: analysis of motility mutants in three animal models. Infect Immun 1991; 59: 2727-2736. 